\title{
BEYOND THE CAKE MODEL: CRITICAL INTERSECTIONALITY AND THE RELATIVE ADVANTAGE OF DISADVANTAGE
}

\author{
Robert Lee Oprisko* \\ Josh Caplan*
}

\begin{abstract}
Intersectionality came about as a critique of traditional, uniaxial studies of oppression. The initial wave argued that the intersection(s) of multiple axes of social construction create uniquely experienced forms of domination and oppression that can only be studied within the context of said intersections. Methodologically, intersectional research has been used primarily as a tool of studying dichotomous intersections of race, gender, and class. However, theoretically focused literature articulates the importance of operating in a more complex understanding of intersectional axes by adding both breadth and depth. Current intersectional studies, therefore, are locked intradeoff between precision and generalizability in any quantitative research and intersect thus far, the power of intersectionality remains unrealized. This paper argues for a large-scale expansion of the number of variables studied in order to gain the most precise understandings of social construction. This creates a tradeoff between precision and generalizability. The power of intersectionality however is not in its generalizability, but rather in its precision for the study of small-n groups. We suggest moving beyond the cake model and into acritical intersectionalitymodel that embraces the agential realism of quantum politics.
\end{abstract}

Keywords: Intersectionality; Methodology; Quantum Politics; Social String Theory; Critical Theory and Human Dignity

\section{Introduction}

Contemporary intersectional research is imprecisely studying systems of oppression and domination, which contributes to the invisibility of unique groups who are even less likely to be studied in the literature and engaged within the policy process. These groups, the least advantaged of the least advantaged, are being hyper-marginalized; they were ignored in early writings but current discourse implies that they are being taken into account when they are still not being engaged adds a level of marginalization. The traits that marginalize these individuals are not inconsequential, but have meaningful implications for their experience in society.

This paper argues for intersectional research to further incorporate the advances within uniaxial studies into their analyses in order to gain a more precise understanding of the social and political experiences of uniquely marginalized groups. Each axis must 
be deconstructed as far as is of momentary critical importance in order to optimize the precision of the model(s). This form of intersectional inquiry is both critical and selfreflective, recognizing the power that external inscription of value plays in systems of structural domination and oppression. Therefore, we argue for researchers to defend the operationalization of their variables at a certain level of precision by engaging with the next most precise level. We assert that this increased precision will, in fact, contribute to greater empirical accuracy in intersectional research. Without adding a greater quantity and quality of axes into intersectionality studies, research projects that rely on intersectionality tend to focus solely on those who are the most advantaged within their sub-category within society while those who are least advantaged will continue to exist invisibly at the margins. This more rigorous form of analysis adds additional context and precision to the studies at the cost of generalizability of the knowledge gained. Intersectionality theory is premised on the idea that context is critical for social construction, and as such grandscale generalizability is significantly at odds with intersectional analyses.

The first section of this paper will articulate this framework and differentiate itself from previous studies of intersectionality. Following that analysis, this paper will briefly illustrate deconstructed theories that have already been created by scholars that are rarely present in intersectionality literature. This latter section will emphasize that the current approaches select for those who are most advantaged and average out the experiences of both the most and least advantaged members of society. Finally, we present a new model for intersectional research that moves intersectionality into the cutting edge of mixedmethodological study.

\section{Framework for Intersectionality}

Intersectionality within this framework will be defined as the unique social experience that occurs when multiple socially constructed axes interact within an individual at a specific time and place. (Oprisko Honor 55-58) This operationalization emphasizes the context of an either explicitly or implicitly defined spatial and temporal context. It also removes the emphasis of oppression in intersectionality, which is present in numerous important works (Bilge; Davis; Nash; Strolovich "Do Interest Groups Represent the Disadvantaged? Advocacy at the Intersections of Race, Class, and Gender"; Syed; Weldon). Individuals exist simultaneously in positions of oppressed and oppressor depending on the issue and framing at hand; intersectionality equally allows for the study and understanding of social advantages just as well as it does with disadvantages. (Warner) An additional substantive concern with using the oppression rhetoric is that it reinforces the impression that one intersection is normal, or good, while an opposing intersection is deviant, or problematic (Foucault Madness and Civilization: A History of Insanity and the Age of Reason; Hegarty and Pratto; Schneider and Ingram; Warner). By separating the process of intersectionality from the rhetoric of oppression, the process becomes phenomenologically sound and lacks an arbitrary constraint. 
The intersectionality literature has largely coalesced around an approach best defined by Weldon (2008) of intersectionality-plus where individuals are constructed by and experience both singular axial constructions as well as unique experiences that can only be accessed at their personal intersection. An individual is constructed along each axis as well as in conjunction with other axes, which create unique experiences; the identification of these unique experiences is what brings scholars into intersectionality. This paper engages in the highly cited and impactful methodology outlined by McCall (2005) called intracategorical complexity. The idea of categories are not rejected as is true for anticategorical approaches, rather they should be qualitatively deconstructed to their most precise forms for use in critical assessment in future research. Even though categories are wholly constructed, as will be shown, they still have the potential of being a critical tool in which to engage the internal organization of individuals. This approach allows for the researcher to study intersectional groups that are both important to the particular research study and practically invisible, heretofore unseen as a unique presentation of intersected identities with socio-political relevance, while not being constrained to a set number of arbitrarily delineated social structures that may or may not prove most relevant to the research.

All categorizations are, by their nature, socially constructed through the discursive creation of reality (Rawls; Sessions). The categorical identities that individuals both assume and with which they are inscribed are the collected norms and understandings of appropriateness that are internalized, and externally projected, by individuals and the groups with which they associate. Specifically, the ideas, images, and symbols that individuals associate with determined traits are simultaneously aggregates and interactions within a society of discursively agreed upon understandings of a given phenomenon along with normatively appropriate prescriptions (Foucault Madness and Civilization: A History of Insanity and the Age of Reason; Rabinow; Risse; Foucault Discipline and Punish).

Relying on deeply reductionist categories marginalize significant individuality and diversity within members of the category not as an externality, but as an intention. The rational for using simplistic typologies is that the actual construction of an individual promises to be excessively complex, fluid, and ultimately unworkable; rather than directly engage such complexities, these typologies seek to gain knowledge through highly indirect proxies. Fortunately, scholars in their respected social fields have deconstructed the broad and highly marginalizing terms of race, (Williams; Lieberman and Reynolds; Manly; Abel) gender, (Knights; Deutscher; Sieber; Goldner) and class, (Fuchs; Goldthorpe; Pintelon et al.; Ashley and Empson; Anthias). along with other axes, into numerous concepts and proxies that are collectively more precise than these initial umbrella terms. The advocacy of this paper is to deconstruct the categories as far as is theoretically possible and use these diverse and more precise measures, in conjunction with other constructions, to

Epiphany: Journal of Transdisciplinary Studies, Vol. 7. No. 2, (2014) (C) Faculty of Arts and Social Sciences 
both recreate and discover the social and political experiences of individuals within the framework of intersectionality. This type of work has been done, (LaVaque-Manty) and should represent the standard to which future intersectional research should strive.

In several influential works on intersectionality, the question arises as to what axes are relevant and which ones are simply superfluous and risk throwing the research into an infinitely regressive system (Lewis; Weldon; Young). This paper will make two arguments on this front. First, the value of intersectionality is the deeply contextualized viewpoint that it creates; simply put, if the bottom of the rabbit hole is an incredibly small- $n$ group, this allows for the researcher to gain incredible depth even if it is hardly generalizable. There is no reason to approach sociological or political studies with a preconceived quantitative unit threshold before a group gains relevant size; there is no a priori basis to reject the possibility of a group of one existing in a meaningful manner, rather it is the responsibility of the researcher to show that a group is or is not socially meaningful, politically salient, or unique oppressed (Wlezien; Duncan; Duncan and Stewart)_ With this noted, it is difficult to think of a significant number of social or political experiences that are salient to a group of one while either completely lacking salience or existing in a fundamentally different manner to other individuals.

Second, researchers should engage as many axes as possible in as many combinations as is allowable in order to determine the salience of the intersectional group(s) for the research being conducted. We concur with Analouise Keating that researchers are often "normalize[d] and naturalize[d]" in "the existing social system, values, and standards so entirely that they deny the possibility of change." (Keating, 83) With a priori assumptions of salient identity groups as variables, scholars are not truly testing the key independent variable of intersectionality - identity. In many ways, it is an arbitrary limitation of intersectional models, similar to allowing only integers into one's mathematical reality.

By accepting the social-construction of reality, each research agenda is focused on a critical moment in time and space, which presents a unique social hierarchy predicated on the valuation and evaluation of individuals and sub-groups within the group that represents the level of analysis (Oprisko Honor 29-39). Kornprobst (2011) argues that systems of hierarchical authority, which is both the foundation for intersectionality studies and the academic community, result from unequal levels of persuasiveness and receptivity. He shows that experts are able to present their own expertise as a successful defense for their arguments, rather than relying on the logic of argument itself (Kornprobst 74-76). While such success is possible, it does not provide the community with better research. A necessary part of any research project is an explanation for the inclusion of every given variable; researchers using intersectionality should be equally pressed in justifying why they do not include an axis of construction as they are for including one. The level of

Epiphany: Journal of Transdisciplinary Studies, Vol. 7. No. 2, (2014) (C Faculty of Arts and Social Sciences 
deconstruction should show that further deconstruction does not offer greater or more meaningful insight in relation to the phenomenon at hand. Salience should be determined, not assumed. The premise behind intersectionality is that experiences are buried by a rush to study primary constructions without looking at the intersections between other axes; Purdie-Vaughns and Eibach (2008) refer to this phenomenon as intersectional invisibility where individuals who are outside of the predetermined norm are ignored or marginalized. It is nearly axiomatic that some intersections are more meaningful than others, (YuvalDavis "Belonging and the Politics of Belonging"; Yuval-Davis "Intersectionality and Feminist Politics") however this does not justify the automatic exclusion of studying other intersections within a research program. Continuing to focus on a small number of intersections diminishes the power and rigor of intersectionality as a method by structuring the literature to perceive only a small number of intersections as meaningful. Failing to sufficiently situate our research further entrenches the invisibility of individuals and groups that exist at more precise intersections.

The act of grouping potentially meaningful sub-categories into larger, more general categories marginalizes the critical differences that intersectionality is trying to ferret out. The act of using a category such as "African-American" as the most precise measure washes out the significant dynamics within that group. The marginalization of axes of oppression in a research program, the "etc." of possible axes, has the direct effect of marginalizing those who are constrained within them. (Butler; Ludvig) While Butler's (1990) argument of marginalization is widely cited and agreed upon, the actual operationalization of intersectionality works tend to still fall into this paradox of marginalizing individuals while trying to study invisible groups.

Strolovich $(2006,2007)$ argued that the value of intersectionality is that it allows for one to study the least advantaged within uniaxial approaches. Research and advocacy tends to focus on members of the group that are by their nature better advantaged than other members of the group; women's groups tend to focus on issues that impact white women more than they impact black women. This project seeks to expand this rhetoric by focusing on the hierarchy within the "least advantaged". The most advantaged of the least advantaged are defined as being individuals who are disadvantaged within highly imprecise measures, such as the studies of black women having a fundamentally different experience than the simply cumulative effect of both axes as already described, (Crenshaw) yet are more advantaged or have a fundamentally different experience than those who fall under the same measures, but are disadvantaged by more precise measures within the axes, such as the challenges that face black women with darker skin tone that black women with lighter skin tone do not face, (Hunter) as will be shown later. The darker skin toned individuals are, therefore, the relatively less advantaged of the least advantaged and face challenges that the relatively more advantaged of the least advantaged do not. Thus for a study that studies the impact of skin-tone on economic advantage of young, black women, the hypothesis would be that women with the darkest skin-tone would be the least 
advantaged of the least advantaged.

The implication of extrapolating the Strolovich framework is that it shows how experiences, hierarchies, and complexities of social construction are marginalized when intersectionality is not rigorously employed as a research methodology. Rather than provide greater context for understanding the experiences of individuals, traditional intersectionality approaches can marginalize the experiences of both the advantaged and disadvantaged within the intersection; the most advantaged are perceived of as being worse off than is factual, while the least advantaged are perceived as being better off, and neither gain precise nor accurate measures of their experiences. Although there may always be a further possible delineation that could potentially produce a split between advantages and disadvantages within a sub group, it is critical that the deconstructions that have been discovered be incorporated. As previously noted, it is possible that the experiences are different without a clear advantage or disadvantage between the groups.

The importance of adding this rigor to intersectional studies has nothing to do with the denigration of past research and everything to do with maintaining the humanity and dignity of the individuals that form the groups being studied. (Oprisko "The Rebel as Sovereign") Intersectionality is premised upon the need not to ignore the marginalized and is therefore self-immolating when it caters to the statistical norms while dismissing both extreme cases and the standard error. The marginal groups, the statistically insignificant are supposed to be the primary concern within intersectional studies, and providing dignity to these groups is the purpose and duty of the researcher.

\section{Methodological Concerns}

With the intersectionality approach previously articulated, there is the potential for criticism in regards to the logistics of the methodology. Intersectionality is a process or a framework through which individual situations are understood as being constitutively created and influenced by the context of their environment. It is not a mere methodological tool in the same way as logit regression or surveys are; rather it is a theoretical tool that aids and directs the researcher in methodically uncovering experiences or constructions that would otherwise be invisible (Davis; Purdie-Vaughns and Eibach; Syed; Warner; Weldon). This definition does not prima facie prescribe a methodological approach for studying complex, constitutively constructed individuals. However there are predispositions associated with both quantitative and qualitative methods, which give both options strengths and weaknesses. While quantitative studies are often credited with uncovering large scale trends within data, qualitative methods tend to allow for more comprehensive descriptions of a phenomenon and the uniqueness that causes it either to stand out or to be representative of a greater trend (King, Keohane and Verba; Van Evera). It is the descriptive comprehensiveness of the qualitative methods that have made them the predominant approach, but it is not necessarily the only approach that can be

Epiphany: Journal of Transdisciplinary Studies, Vol. 7. No. 2, (2014) (C) Faculty of Arts and Social Sciences 
used within intersectionality (Cole; Mahalingam; Shields; Yuval-Davis "Intersectionality and Feminist Politics") McCall (2005) notes that the descriptive power of case studies allows for researchers to understand newly discovered groups before choosing additional appropriate methodologies.

The primary methodological concern with using a multitude of highly precise axes is that readily available data may not operationalize individuals with enough precision. This is especially a concern when using common data sets; the data may allow for studies of individuals based on sex, uni-axial race, or income bracket, but there are few if any data sets that engage other axes of oppression, such as sexuality, skin tone, or physical and emotional conditions. It is within these axes that the least advantaged may dwell. While employing statistical models with data can create interesting arguments that are potentially generalizable, (Darity Jr. and Mason; Dottolo and Stewart; Holmsten, Moser and Slosar) there is a clear tradeoff. As already shown, the push towards generalizability fundamentally contrasts with the purpose of intersectionality.

Hunter (2005) showed both the difficulty in creating a data set using intersectionality as well the benefits of having one created. In order to study the effect of skin tone on job and life prospects of African American and Mexican American women, Hunter used specific and probing interviews that asked in-depth questions, with necessary follow up, of a representative sampling of these groups about their experiences. What makes the Hunter approach stand out is the combination of resisting the urge to use easily accessible members of the community while ensuring that the subjects are analytically and theoretically accurate representatives of their respective constructions, and creating a data set that operationalized her subjects along a large number of axes (Hunter). Datasets like these that collect every identity of the individual have the advantage of being usable in non-intersectional studies while still retaining their higher precision that optimizes them for intersectionality (Yuval-Davis "Intersectionality and Feminist Politics")

Gathering data on axes can also be difficult due to the potential differences between the internal and external associations. While an individual associates with one characterization, the norm of that category may believe, and act, in a manner that associates the individual with a mutually exclusive category. Intersectionality is predicated on the complexity of identity which embraces plural affiliation, (Sen) personal political salience, (Duncan and Stewart) the economy of esteem, (Brennan and Pettit) and dynamic tension between external inscription and the personal introjection of identity (Oprisko Honor). Scholars should not assume that multiple identifications cleanly complement each other (Yuval-Davis "Belonging and the Politics of Belonging"). In engaging these possibilities, the researcher must cross-reference the criterion for inclusion from the group with the criterion used by the individual in question; in instances where there is a difference in criteria, researchers should investigate the reasoning before proceeding with the labeling

Epiphany: Journal of Transdisciplinary Studies, Vol. 7. No. 2, (2014) (C Faculty of Arts and Social Sciences 
of an individual as belonging to a certain category. Although intersectionality clearly focuses upon the structure of identification, it is important to use a complex engagement of identity in order to best delineate which group(s) is being oppressed by which other (probably overarching) group. this will determine the appropriate level of analysis.

\section{The Deconstruction of Gender}

Through the system that has been promoted by numerous intersectionality scholars in regards to the use of gender, one can only see an entrenchment of the archaic and obsolete notion that there can only be two sexes which neatly correspond to two complementing genders, which are exclusive, immutable, and static. The breadth of those that are marginalized within these projects is as unquestionably vast as it is unnecessary. A dichotomous understanding of gender has been rejected as not being meaningful (Ludvig). Despite using the moniker of gender, many intersectionality papers are in fact engaging sex through their focus on physical manifestation of the individual, which ignores issues of gender and sexuality, both of which focus on the sociological constructions of physical manifestation (Risman). In the interest of space, this paper will briefly focus on the implications of eschewing the deconstruction of sexuality and of the dichotomous operationalization of sex.

Sexuality

The a priori assumption in engaging the social construction of gender is that there is a male experience that is largely experienced by all males within the population and a female experience that is largely experienced by all females and that these two experiences may or may not be different. This corresponds to the propensity in American society of a heteronormative range in which an individual falls in relation to their degrees of masculinity/femininity and sexuality. Existing outside of this framework, the individual may experience hostility and oppression, or some form of unique interactions between those that propagate the heteronormativity and the individual. Heteronormativity describes the tendency for default assumptions of gender and sexuality to be heterosexual with women consisting overwhelmingly of feminine characteristics and men to be overwhelmingly masculine characteristics (Duerst-Lahti; Hegarty and Pratto; Hegarty, Pratto and Lemieux; Lippa; Nielson, Walden and Kunkel).

However when individuals who are homosexual or identifying with an opposing gender identity, i.e. a masculine female or a feminine male, they potentially clash with the heteronormative framework that is relevant to their specific time and place. These clashes have the potential of fundamentally altering their experiences and interactions with society (Lippa; Nielson, Walden and Kunkel). There are two primary constructions that are at the greatest risk of having their experiences impacted by clashes with heteronormative barriers. The first is homosexuality, which in American society leads to a fundamentally unique experience when compared to heterosexuality due to the implicit heteronormative 
values and the explicit actions taken to maintain them (Hegarty, Pratto and Lemieux). Homosexuals are systemically approached as committing an act of sexual deviance of such odious proportions that one's enemies, or the hated others, are often attributed as having homosexual tendencies or characteristics (Puar). Such actions and individuals are framed as being dangerous to society, the public, and morality, and need to be hindered and denigrated at every opportunity; (Hegarty, Pratto and Lemieux) reference conflicts over openly serving in the military or marriage rights for explicit examples.

While theorists reference the value of an intersectionality approach for understanding the construction of homosexuality, (Warner; Weldon) and interesting and engaging work on it has been completed, (See Anderson and McCormack) the implications of sexuality cannot be accessed in a framework that engages gender solely through a dichotomous variable of sex. Hutchinson (1999) showed that within the framework of least advantaged that would later be described by Strolovich (2006) that lesbians are uniquely marginalized in discussions of advantages; groups that seek to merge sexual and racial advocacies at first tend to ignore the implications of homosexuality, but when they do engage it they do so through a masculine framework that disproportionately focuses on gay men rather than lesbian women. This degree of analysis is often hidden by heteronormativity within a male-female breakdown of sex.

The second construction that is hidden by the conflation of gender and sex are individuals who are transgender, or self-identify with a gender identity that does not correspond to the norms dictated by their biological sex. These individuals are often perceived of as being aberrations or caricatures of deviance within the national discourse (Cooper). As a result of conflicting with heteronormative presuppositions, highly stigmatized transgendered individuals, especially among the youth, have a dramatically higher rate of depression and suicide (Clements-Noelle, Marx and Katz). This is indicative of a social experience being significantly harsher and more negative than for those who are not transgender. Identifying these experiences, along with identifying the transgendered individuals themselves, is impossible without a more precise operationalization procedure.

Gender scholars have created a wide range of methods for studying a further deconstructed view of sex, and intersectionality scholars should use similar frameworks. Intersectionality works should engage issues of sexuality, measures of self-identified gender that are independent of sex, as well as attempt to identify heteronormative structures of social control within the time and space of the study (Speier). By engaging in this precision, a more complete understanding of the construction of both individuals and interactions can be performed.

\section{The Deconstruction of Race}

Throughout intersectional writings, there is a tendency to approach racial categorization as a dichotomous variable of "black or white" (Cole and Omari; Collins; Crenshaw; Goff, 
Thomas and Jackson; Mansbridge). This observation should not be interpreted as universal, but as a trend (Hunter; Strolovich "Do Interest Groups Represent the Disadvantaged? Advocacy at the Intersections of Race, Class, and Gender"; Strolovich Affirmative Advocacy: Race, Class, and Gender in Interest Group Politics). The concern is that the social implications of race, which should not be confused with ethnicity, are highly nuanced, subtle, and significant in the individual's construction and as such is best understood with as much attention and definitiveness as possible within the operationalization.

The question of belonging within a racial group is not a small matter. Due to the political and sociological significance of race in the U.S., combined with the ambiguity in defining racial categories, belonging has become a point of tension and conflict both within racial groups as individuals decide who belongs and who does not, and across racial groups as individuals struggle with the implications of categorization (Kennedy; YuvalDavis "Belonging and the Politics of Belonging"). Operating on a dichotomous level is insufficient at best and meaningless at worst; more accurate and precise operationalization is needed to explain race as experienced.

We have become so accustomed to indentifying each other based upon skin color, physiological features, and other external markers that we assume racial categories are factually accurate, unchanging and homogeneous. Ironically, these assumptions - coupled with our daily unthinking references to "race" - create "race," making it more permanent and inflexible (Keating 83).

This paper will explore the idea of multiracialism and colorism as examples of racial theories that emphasize the significant constraints of a dichotomous approach to race.

\section{Multi-racialism}

A dichotomous approach to racial identification marginalizes those that self-identify as multiracial. By engaging in a measurement that approaches individuals as belonging to one racial category or another, individuals who identify with multiple categories are either not taken into account within the research program, are forced to pick one internal identification over another, or are exist as marginal members, never integrated with either identity. Multiracial individuals may find themselves to be strangers in familiar territory, exiles at home, and existentially other in all groups with whom they may seek to identify (Camus).

Hunter (2005) observes that subjects who have one Caucasian parent and one African American parent may either feel alienated from both communities and seek to associate with similar biracial individuals, in effect creating their own racial category, find acceptance in one category but not another, or move seamlessly and comfortably between

Epiphany: Journal of Transdisciplinary Studies, Vol. 7. No. 2, (2014) (C Faculty of Arts and Social Sciences 
both categorizations. Granting that there is highly significant middle ground between these scenarios, the Hunter analysis shows that dichotomous or even multi-categorical classifications of race have a disparate impact on multiracial individuals; rather than fitting in either/or categories, individuals can potentially, and in all likelihood, probably, exist in both/neither categorization. The implication of this is that individuals who exist in non-uniaxial constructions of race are being categorized in a manner that excludes them or marginalizes their experiences into that of an approximate racial category.

\section{Skin tone and colorism}

Even if one were to engage in a research program that assumed the validity of singleracial categories, there is a rich literature showing that there are significant differences in the experiences of individuals within one race based on their skin tone. Studies on skin tone, or racial stratification, show that there is an economic and social hierarchy, or propensity for class based distinctions, based on the darkness of ones skin within the racial group (Hunter). Some studies have shown that skin tone is a better predictor for economic success than the socioeconomic position into which an individual is born (Keith and Herring). Colorist biases occur both within and across racial categories (Maddox and Gray).

Research on skin tone has coalesced around social perceptions of beauty and intelligence as directly correlating with the degree of whiteness that an individual possesses. This is determined by the prominence of white features, such as straight hair, light colored eyes, and light skin tone. Individuals who are perceived as being more white within their racial category are more likely to be able to access higher paying and more stable careers with a greater likelihood of promotion than those who are less white (Hunter; Maddox and Gray).

The implications for incorporating this analysis into intersectionality are clear and significant; while colorism affects both genders, it impacts women far more than men (Thompson and Keith). Holding background variables constant, light skin African American and Mexican American women consistently have higher incomes, lengthier education histories, and more stable marriages due to resources being allocated disproportionately between light and dark skin women (Goldsmith, Hamilton and Darity Jr.; Hunter; Thompson and Keith). The role of colorism is not solely subconscious; women, across racial categories, have harmed or killed themselves using chemicals to bleach their skin or straighten their hair in order to be perceived as whiter and more marketable (Charles; Hall; Li et al.). Color bias is systemic. Medical professionals have been found to work harder, by performing statistically more tests and requiring longer hospital stays, for lighter-skinned individuals within a racial category (White-Means et al.). 
All intersectionality research that operationalize using unnecessarily imprecise measures such as dichotomous-race or racial clumping, are marginalizing the racially least advantaged who, as a result of their placement within the skin stratification hierarchy, are at risk of unique challenges and experiences. Incorporating skin tone into surveys that require self-reporting may be questionably effective as respondents may not be precise in stating their skin tone based on a provided scale due to the potentially subjective nature of the measurement; (Keith and Herring) however, this may not substantially differ from self-reported responses to many other variables, such as income or sexuality (King, Keohane and Verba). Effective operationalization strategies rely on the interviewer deciding independently of the belief of the individual due to the interviewer being trained to identify tone in accordance with a standardized measure (Hunter; Keith and Herring; White-Means et al.).

\section{Beyond the Cake Model}

We argue for the adoption of a refined and more robust model for intersectionality. Intersectionality can and should be viewed as a theory/method that requires dialectic engagement between the researcher and the researched. The most imperative facet of intersectional studies is that they were developed in order to fight against the structural oppression of precise groups who are not recognized as unique by the social-structure, which leads to a loss of human and personal dignity (Oprisko "The Rebel as Sovereign"). As academics and researchers, we operate within a hierarchical structure where our judgments can either illuminate the unique plight of intersectional groups, or reinforce said plight through a lack of due diligence (Kornprobst; Keating). It is important to remember the human impact of research; the operationalization of variables represent the values that are inscribed onto the real persons who form the units of analysis and whom may become subjectified (Heller; Foucault "The Subject and Power"). Because intersectionality seeks to illuminate structural oppression, the most salient point of concern for intersectional studies is precisely where the introjected self-identification of a person does not dovetail with external inscriptions of value(s). Thus, we break with the Cartesian universal epistemology that focuses on a single positive truth in favor of Weinstein's particularistic interdependence. The onto-epistemology moves toward Bohr as articulated by (Barad) and agential realism, which focuses on an agent-object model rather than a subject-objectobserver model. Our move in this direction is premised on identity being an agential performance: identity is a product of action that form agential cuts - valuation and evaluation (Oprisko Honor). Furthermore, acts of identification always necessarily fail to define the object comprehensively, diminishing the totality of the object by the agent (Zizek 959-61). This epistemological shift benefits from a terminological shift from levels of analysis to realms of action and from units of analysis to aspects and phases of action (Weinstein "New Ways and Old to Talk Politics" 44-46). This change not only allows for locational and temporal shifts in the "structure and arrangement of empirical phenomena," but also reinforces the agency of the act of identification: it is important to remember that

Epiphany: Journal of Transdisciplinary Studies, Vol. 7. No. 2, (2014) (C) Faculty of Arts and Social Sciences 
structural oppression is a result of those acts (Weinstein "New Ways and Old to Talk Politics" 46).

Brennan and Pettit view social-value through an economic/transactional lens and suggest that there are groups to which individuals actively seek inclusion and those to which individuals are placed regardless of their will (2005). Their focus is on elite individuals who act in ways that are mutually advantageous, thus defending the position and excellence of the most advantaged of the most advantaged. Oprisko argues that systems of hierarchical oppression are rooted in honor-systems (external value) which are contested by individuals (rebels) and groups (revolutionaries) who defend the dignity of being different (2012a). He elaborates with a social string theory, showing identitarian variables that are externally deemed to be significant are thick, or easily perceived whereas identitarian variables that are internally deemed to be significant are dense, or difficult to compromise (Oprisko Honor 154-55). However, he argues for researchers to do due diligence in asking the research subjects what aspects of their identity are most important to them within the moment of critical inquiry. The degree of internalization for an identity determines its density, or how meaningful it is to the individual. By engaging with how persons self-identify and are identified by others, it becomes possible to determine where there is not only structural oppression premised upon identitarian inequality, but also where the inscription of identity presents a source of conflict.

Our proposed critical intersectionality model suggests that the salience of any variable or intersection of variables is situated and positioned in time and space and are not transferable. Each moment of critical inquiry must include a rigorous methodological treatment to discover which intersectional and autonomous identitarian values are most salient without making assumptions from historical analogy that aren't reverified. However, critical intersectionality invites meta-analyses of intersectional research to study systemic trends in oppression and to trace the effectiveness of programs to reduce sustained and continuous structural violence. However, such models will only work because researchers must determine, in dialogue with subject groups, which aspects of identity are relevant. When research shows that the intersectional variables that define the oppressed are disappearing, we know that progress is being made. If said variables are changing, researchers can track the effects of policy initiatives to determine if said policy is initiating a transfer in structural violence (a different intersectional variable-set is being negatively affected by said policy that helps the original intersectional variable-set) or that the policy is producing gradual positive results (the identitarian values in intersection must increase precision in order to remain significant).

Critical intersectionality moves beyond Weldon's cake model and intersectionalityplus not by suggesting that she was incorrect in stating that the identitarian variables combine to form something altogether different, but in that the cake is static. People change

Epiphany: Journal of Transdisciplinary Studies, Vol. 7. No. 2, (2014) (C Faculty of Arts and Social Sciences 
and societies change. As an individual gets older, they will remain themselves, but they will be different versions of themselves (Weinstein Meaning and Appreciation: Time and Modern Political Life). Similarly, external perception of acceptability will change; action is reality - the realization that the actual event fails to achieve the ideal (Oprisko "Failure as the Real"). An individual with an eighth-grade reading level is considered normal in the eighth-grade, but is considered advanced if in the second-grade, however pockets of adults who do not exceed an eighth-grade reading level are indicative of an education system that suggests structural oppression in a focused direction. Critical intersectionality will thus prove to be exceptionally effective in determining whether certain structures of oppression are limited in time and space or is indicative of a pervasive social problem.

We believe that a better representation for critical intersectionality lies in strings. If we accept that each person is a combination of multiple internal and external identities, those identities combine much like the tex and strands of a string twist around one another. Each strand represents a relational identity: mother, student, light-skinned, AfricanAmerican, etc. External importance can be represented in terms of thickness, or visibility. Internal importance can be represented in terms of density. In terms of the cake model, we hold that each individual person is not only a unique combination of ingredients, but that the ratio of said combination is contingent upon the active engagement of the individual within a realm of action at a critical moment. In terms of our social string theory, certain identities may appear to be invisible, but that does not diminish the density felt by the individual; similarly, certain identities may appear to be dominant, but they may or may not impact a specific realm of action. As a person ages, their string grows longer and they, as a holistic and indivisible person weaves themselves throughout a network of equally complex individuals forming "the fabric of society and the tartans of civilization" (Oprisko Honor 154-55).

The salient identities in social engagement bind individuals to each other and to groups. Singular affiliation would resonate similarly to a pure note on a stringedinstrument; more complex relationships will resemble chords. Every relationship is different, unique, but can be generalized by note. This is the power of intersectionality - to determine the most powerful position in the trade-off between generalizability and specificity, enabling highly precise engagement at the salient realm of action.

\section{Conclusion}

This paper has shown that numerous works in intersectionality have focused on the most advantaged members of a given intersection by operating in archaic and highly imprecise dichotomous measures of social construction. Within all socially constructed axes, with this paper focusing on the most popular ones of gender and race, theorists have uncovered valuable deconstructions and nuances that better articulate the complexity and fluidity of individual construction. Intersectionality authors have largely bypassed these 
deconstructions in favor of less rigorous but more easily obtained and employed measures, such as conflating gender and sex with measures of male or female. This paper does not argue that interesting and meaningful observations cannot be generated by this approach. We do, however, argue that such research runs contrary to the founding principles of intersectionality that focus on the critical importance of contextualization and precision in studying systems of oppression and domination.

This paper noted that differences between groups of individuals do not necessitate salience within those differences; the context in which they exist can provide, maximize, or minimize the salience of a given organization (Posner). This paper has argued that every possible axis must be investigated in order to determine if there is salience with it singularly or within the context of other axes. After investigating, it is necessary for the researcher to explain not only the rationale for the axes and levels of deconstruction that they chose, but also for those that they did not. We emphasize the importance of the dialectic model of critical intersectionality in order to minimize the structural oppression inherent within academic research. This model provides the best solution thus far between precision and generalizability in intersectionality studies. It allows for both external perception and internal introspection. It both requires research to focus on individual moments of critical inquiry and provides a logical argument for longitudinal analyses that can study the effects of policy on structural oppression. It allows for changes within individuals and within groups and accounts for the structural oppression inherent within intersectionality studies themselves.

The most significant axes to explore illuminate the most invisible groups of intersectionality. We find that it is the uniquely marginalized groups, the radically oppressed, who are arguably the most important subjects for examination with intersectionality as a theory/method. These statistically insignificant groups of individuals are the most socially significant because they reflect the society's depth of devotion to the ideals of human dignity.

\section{References}

Abel, Elizabeth. "Black Writing, White Reading: Race and the Politics of Feminist Interpretation." Critical Inquiry 19.3 (1993): 470-98. Print.

Anderson, E., and M. McCormack. "Intersectionality, Critical Race Theory, and American Sporting Oppression: Examining Black and Gay Male Athletes.” Journal of Homosexuality 57.8 (2010): 949-67. Print.

Anthias, Floya. "Hierarchies of Social Location, Class, and Intersectionality: Towards a Translocational Frame.” International Sociology 28.1 (2013): 121-38. Print.

Ashley, Louise, and Laura Empson. "Differentiation and Discrimination: Understanding Social Class and Social Exclusion in Leading Law Firms.” Human Relations 66.2 (2013): 219-44. Print.

Barad, Karen. Meeting the Universe Halfway: Quantum Physics and the Entanglement of Matter and 
Meaning. Kindle ed. Durham, NC: Duke University Press, 2007. Print.

Bilge, Sirma. "Recent Feminist Outlooks on Intersectionality.” Diogenes 57.1 (2010): 58-72. Print.

Brennan, Geoffrey, and Philip Pettit. The Economy of Esteem: An Essay on Civil and Political Society. Kindle ed. New York, NY: Oxford University Press, 2005. Print.

Butler, Judith. Gender Trouble: Feminism and the Subversion of Identity. New York, NY: Routledge, 1990. Print.

Camus, Albert. "Exile and the Kingdom." Trans. O'Brien, Justin. The Plague, the Fall, Exile and the Kingdom, and Selected Essays. 1957. Everyman's Library ed. New York, NY: Alfred A. Knopf, 2004. 357-488. Print.

Charles, Christopher. "Skin Bleaching, Self-Hate, and Black Identity in Jamaica.” Journal of Black Studies 33.6 (2003): 711-28. Print.

Clements-Noelle, K., R. Marx, and M. Katz. “Attempted Suicide among Transgendered Persons: The Influence of Gender-Based Discrimination and Victimization." Journal of Homosexuality 51.3 (2006): 53-69. Print.

Cole, Elizabeth. "Intersectionality and Research in Psychology." American Psychologist 64.3 (2009): 17080. Print.

Cole, Elizabeth, and Safiya Omari. "Race, Class, and the Dilemmas of Upward Mobility for African Americans." Journal of Social issues 59.4 (2003): 785-802. Print.

Collins, Patricia. "It's All in the Family: Intersections of Gender, Race, and Nation." Hypatia 13.3 (1998): 62-82. Print.

Cooper, Brenda. “Boys Don’t Cry and Female Masculinity: Reclaiming a Life and Dismantling the Politics of Normative Heterosexuality." Critical Studies in Media Communication 19.1 (2002): 44-63. Print.

Crenshaw, Kimberle. "Mapping the Margins: Intersectionality, Identity, Politics, and Violence against Women of Color.” Stanford Law Review 43.6 (1991): 1241-99. Print.

Darity Jr., William, and Patrick Mason. "Evidence on Discrimination in Employment: Codes of Color, Codes of Gender.” Journal of Economic Perspectives 12.2 (1998): 63-90. Print.

Davis, Kathy. "Intersectionality as a Buzzword: A Sociology of Science Perspective on What Makes a Feminist Theory Successful.” Feminist Theory 9.1 (2008): 67-85. Print.

Deutscher, Penelope. Yielding Gender: Feminism, Deconstruction, and the History of Philosophy. New York, NY: Routledge, 1997. Print.

Dottolo, Andrea, and Abigail Stewart. "Don't Ever Forget, Now, You're a Black Man in America: Intersections of Race, Class, and Gender in Encounters with the Police." Sex Roles 59.2 (2008): 350-64. Print.

Duerst-Lahti, Georgia. "Gender Ideology: Masculinism and Feminism.” Politics, Gender, and Concepts: Theory and Methodology. Eds. Geortz, Gary and Amy G. Mazur. Cambridge, UK: Cambridge University Press, 2008. Print.

Duncan, Lauren E. "Personal Political Salience as a Self-Schema: Consequences for Political Information Processing.” Political Psychology 26.6 (2005): 965-76. Print.

Duncan, Lauren E., and Abigail Stewart. "Personal Political Salience: The Role of Personality in Collective Action and Identity.” Political Psychology 28.2 (2007): 143-64. Print.

Epiphany: Journal of Transdisciplinary Studies, Vol. 7. No. 2, (2014) (C) Faculty of Arts and Social Sciences 
Foucault, Michel. Discipline and Punish. Trans. Sheridan, Alan. Vintage ed. New York, NY: Random House, 1995. Print.

---. Madness and Civilization: A History of Insanity and the Age of Reason. New York, NY: Random House, 1965. Print.

---. “The Subject and Power.” Critical Inquiry 8.4 (1982): 777-95. Print.

Fuchs, Christian. Deconstructive Class Analysis: Theoretical Foundations and Empirical Examples for the Richness and the Class Analysis of the Media and the Culture of Industry. Salzburg, Austria: ICT\&S, 2008. Print.

Goff, Phillip, Margaret Thomas, and Matthew Jackson. “Ain’t I a Woman?: Towards an Intersectional Approach to Person Perception and Group-Based Harms.” Sex Roles 59.2 (2008): 392-403. Print.

Goldner, Virginia. "Ironic Gender/Authentic Sex." Studies in Gender and Sexuality 4.2 (2003): 113-39. Print.

Goldsmith, Arthur, Darrick Hamilton, and William Darity Jr. "From Dark to Light: Skin Color and Wages among African-Americans.” The Journal of Human Resources 42.4 (2007): 701-38. Print.

Goldthorpe, John H. "The Promising Future of Class Analysis: A Response to Recent Critiques." Sociology 26.3 (1992): 381-400. Print.

Hall, Ronald. "The Bleaching Syndrome: African American's Response to Cultural Domination Vis-a-Vis Skin Color.” Journal of Black Studies 26.2 (1995): 172-84. Print.

Hegarty, Peter, and Felicia Pratto. "The Differences That Norms Make: Empiricism, Social Constructionism, and the Interpretation of Group Differences.” Sex Roles 50.7 (2004): 445-53. Print.

Hegarty, Peter, Felicia Pratto, and Anthony F. Lemieux. "Heterosexist Ambivalence and Heterocentric Norms: Drinking in Intergroup Discomfort.” Group Processes and Intergroup Relations 7.2 (2004): 119-30. Print.

Heller, Kevin J. "Power, Subjectification, and Resistance in Foucault." Substance 25.1 (1996): 78-110. Print.

Holmsten, Stephanie, Robert Moser, and Mary Slosar. “Do Ethnic Parties Exclude Women?” Comparative Political Studies 43.10 (2010): 1179-201. Print.

Hunter, Margaret. Race, Gender, and the Politics of Skin Tone. New York, NY: Routledge, 2005. Print.

Keating, Analouise. "From Intersections to Interconnections: Lessons for Transformation from "This Bridge Called My Back: Radical Writings by Women of Color"." The Intersectional Approach: Transforming the Academy through Race, Class, and Gender. Eds. Berger, Michele Tracy and Kathleen Guidroz. Chapel Hill, NC: The University of North Carolina Press, 2009. 81-99. Print.

Keith, Verna, and Cedric Herring. "Skin Tone and Stratification in the Black Community." American Journal of Sociology 97.3 (1991): 760-78. Print.

Kennedy, Randall. Sellout: The Politics of Racial Betrayal. New York, NY: Random House, 2008. Print.

King, Gary, Robert O. Keohane, and Sidney Verba. Designing Social Inquiry: Scientific Inference in Qualitative Research. Princeton, NJ: Princeton University Press, 1994. Print.

Knights, David. "Organization Theory in the Age of Deconstruction: Dualism, Gender, and Postmodernism Revisited.” Organization Studies 18.1 (1997): 1-19. Print.

Kornprobst, Markus. "The Agent's Logic of Action: Defining and Mapping Political Judgement." International Theory 3.1 (2011): 70-104. Print.

Epiphany: Journal of Transdisciplinary Studies, Vol. 7. No. 2, (2014) (C) Faculty of Arts and Social Sciences 
LaVaque-Manty, Mika. The Playing Fields of Eton: Equality and Excellence in Modern Meritocracy. Ann Arbor, MI: University of Michigan Press, 2009. Print.

Lewis, Gail. "Celebrating Intersectionality? Debates on a Multi-Faceted Concept in Gender Studies: Themes from a Conference.” European Journal of Women's Studies 16.3 (2009): 203-10. Print.

Li, Eric, et al. "Skin Lightening and Beauty in Four Asian Cultures." Advances in Consumer Research 35 (2008): 444-49. Print.

Lieberman, Leonard, and Larry T. Reynolds. "Race: The Deconstruction of a Scientific Concept." Race and Other Misadventures: Essays in Honor of Ashley Montagu in His Ninetieth Year. Eds. Reynolds, Larry T. and Leonard Lieberman. Lanham, MD: Rowman \& Littlefield, 1996. Print.

Lippa, Richard. "On Deconstructing and Reconstructing Masculinity-Feminity." Journal of Research in Personality 35.1 (2001): 168-207. Print.

Ludvig, Alice. "Differences between Women? Intersecting Voices in a Female Narrative." European Journal of Women's Studies 13.3 (2006): 245-58. Print.

Maddox, Keith B., and Stephanie Gray. "Cognitive Representations of Black Americans: Reexploring the Role of Skin Tone.” Personality and Social Psychology Bulletin 28.2 (2002): 250-59. Print.

Mahalingam, Ramaswami. "Engendering Immigrant Psychology: An Intersectionality Perspective." Sex Roles 59.5 (2008): 326-36. Print.

Manly, Jennifer J. "Deconstructing Race and Ethnicity: Implications for Measurement of Health Outcomes." Medical Care 44.11 (2006): S10-S16. Print.

Mansbridge, Jane. "Should Blacks Represent Blacks and Women Represent Women? A Contingent Yes." Journal of Politics 61.3 (1999): 628-57. Print.

Nash, Jennifer. "Review Essay: Undisciplining Intersectionality.” International Feminist Journal of Politics 11.4 (2009): 587-93. Print.

Nielson, Joyce, Glenda Walden, and Charlotte A. Kunkel. "Gendered Heteronormativity: Empirical Illustrations in Everyday Life.” The Sociological Quarterly 41.2 (2000): 283-96. Print.

Oprisko, Robert L. "Failure as the Real: A Review of Slavoj Zizek's Less Than Nothing: Hegel and the Shadow of Dialectical Materialism.” Theoria and Praxis 1.2 (2014). Print.

---. Honor: A Phenomenology. Routledge Innovations in Political Theory. New York, NY: Routledge, 2012. Print.

---. "The Rebel as Sovereign: The Political Theology of Dignity.” Revista Pleyade.9 (2012): 119-36. Print.

Pintelon, Olivier, et al. "The Social Stratification of Social Risks: The Relevance of Class for Social Investment Strategies.” Journal of European Social Policy 23.1 (2013): 52-67. Print.

Posner, Daniel. "The Political Salience of Cultural Difference: Why Chewas and Tumbukas Are Allies in Zambia and Adversaries in Malawi.” American Political Science Review 98.4 (2004): 529-45. Print.

Puar, Jasbir. "Mapping Us Hmonormativities.” Gender, Place, and Culture 13.1 (2006): 67-88. Print.

Purdie-Vaughns, Valerie, and Richard Eibach. "Intersectional Invisibility: The Distinctive Advantages and Disadvantages of Multiple Subordinate-Group Identities.” Sex Roles 59.1 (2008): 377-91. Print.

Rabinow, Paul. "Introduction.” The Foucault Reader. Ed. Rabinow, Paul. New York, NY: Random House, 1984. Print.

Rawls, John. A Theory of Justice. Kindle ed. Cambridge, MA: Belknap, 1971. Print.

Epiphany: Journal of Transdisciplinary Studies, Vol. 7. No. 2, (2014) (C) Faculty of Arts and Social Sciences 
Risman, Barbara. "Gender as Social Structure: Theory Wrestling with Activism.” Gender and Society 18.4 (2004): 429-50. Print.

Risse, Thomas. "Let's Argue!: Communicative Action in World Politics.” International Organization 54.1 (2000): 1-39. Print.

Schneider, Anne, and Helen Ingram. "Social Construction of Target Populations: Implications for Politics and Policy.” American Political Science Review 87.2 (1993): 334-47. Print.

Sen, Amartya. Identity and Violence. Issues of Our Time. Ed. Gates Jr., Henry Louis. New York, NY: W. W. Norton and Co., 2006. Print.

Sessions, William Lad. Honor for Us: A Philosophical Analysis, Interpretation and Defense. New York, NY: Continuum, 2010. Print.

Shields, Stephanie. “Gender: An Intersectionality Perspective.” Sex Roles 59.5 (2008): 301-11. Print.

Sieber, Sharon. "The Deconstruction of Gender as Archetype in Rosario Castellanos' El Eterno Femenino." Letras Femeninas 25.1 (1999): 39-48. Print.

Speier, Hans. "Freedom and Social Planning." The American Journal of Sociology 42.4 (1937): 463-83. Print.

Strolovich, Dara. Affirmative Advocacy: Race, Class, and Gender in Interest Group Politics. Chicago, IL: University of Chicago Press, 2007. Print.

---. "Do Interest Groups Represent the Disadvantaged? Advocacy at the Intersections of Race, Class, and Gender.” Journal of Politics 68.4 (2006): 894-910. Print.

Syed, Moin. "Disciplinarity and Methodology in Intersectionality Theory and Research." American Psychologist 65.1 (2010): 61-62. Print.

Thompson, Maxine S., and Verna M. Keith. "The Blacker the Berry: Gender, Skin Tone, Self-Esteem, and Self-Efficacy." Gender and Society 15.3 (2001): 336-57. Print.

Van Evera, Stephen. Guide to Methods for Students of Political Science. Ithaca, NY: Cornell University Press, 1997. Print.

Warner, Leah. “A Best Practices Guide to Intersectional Approaches in Psychological Research.” Sex Roles 59.2 (2008): 454-63. Print.

Weinstein, Michael A. Meaning and Appreciation: Time and Modern Political Life. Google E-book ed. West Lafayette, IN: Purdue University Press, 1978. Print.

---. "New Ways and Old to Talk Politics." The Review of Politics 35.1 (1973): 41-60. Print.

Weldon, S. Laurel. "Intersectionality." Politics, Gender, and Concepts: Theory and Methodology. Eds. Goertz, Gary and Amy G. Mazur. Cambridge, UK: Cambridge University Press, 2008. 193-218. Print.

White-Means, Shelley, et al. "Cultural Competency, Race, and Skin Tone Bias among Pharmacy, Nursing, and Medical Students: Implications for Addressing Health Disparities.” Medical Care Research and Review 66.4 (2009): 436-55. Print.

Williams, Rhonda M. "Race, Deconstruction, and the Emergent Agenda of Feminist Economic Theory." Beyond Economic Man: Feminist Theory and Economics. Eds. Ferber, Marianne A. and Julie A. Ielson. Chicago, IL: University of Chicago Press, 2009. Print.

Wlezien, Christopher. "On the Salience of Political Issues: The Problem with 'Most Important Problem'." Electoral Studies 24.4 (1988): 555-79. Print.

Epiphany: Journal of Transdisciplinary Studies, Vol. 7. No. 2, (2014) (C) Faculty of Arts and Social Sciences 
Young, Iris. “Gender as Seriality: Thinking About Women as a Social Collective.” Signs 19.3 (1994): 71338. Print.

Yuval-Davis, Nira. "Belonging and the Politics of Belonging." Patterns of Prejudice 40.3 (2006): 198-214. Print.

---. “Intersectionality and Feminist Politics.” European Journal of Women's Studies 13.3 (2006): 193-209. Print.

Zizek, Slavoj. Less Than Nothing: Hegel and the Shadow of Dialectical Materialism. Brooklyn, NY: Verso, 2012. Print. 